\title{
FEATURES OF FUNCTIONING THE INTEGRATED BUILDING THERMAL MODEL
}

\author{
Maxim N. Morozov ${ }^{1,}{ }^{*}$, Alena O. Zhdanova ${ }^{1}$, and Maksim V. Piskunov ${ }^{1}$ \\ ${ }^{1}$ National Research Tomsk Polytechnic University, 634050 Tomsk, Russia
}

\begin{abstract}
A model of the building heating system, consisting of energy source, a distributed automatic control system, elements of individual heating unit and heating system is designed. Application Simulink of mathematical package Matlab is selected as a platform for the model. There are the specialized application Simscape libraries in aggregate with a wide range of Matlab mathematical tools allow to apply the "acausal" modeling concept. Implementation the "physical" representation of the object model gave improving the accuracy of the models. Principle of operation and features of the functioning of the thermal model is described. The investigations of building cooling dynamics were carried out.
\end{abstract}

\section{Introduction}

When creating complex models of a heating system, as a rule, the occurrence of difficulties is usually caused by following requirements (for example, to highlight works [1-6]):

1) simulation of individual components of building life support systems (for example, the control system, heating appliance, heat exchanger, etc.);

2) maintenance of model functioning in a wide temperature range.

Solution of the first problem is to find a compromise between the model description completeness and its adequacy and accuracy of studied system reproduction. The choice of internal and external influencing factors (which must be also adequately reproduced) variety is an important step in developing of the model. Excessive accuracy influences negatively on the capabilities of a computer, increasing simulation time. When solving the problem as a part of this work, there were used approaches, described in $[7,8]$.

Another no less important problem is to extend the temperature range of model operating. This is necessary condition for the investigation of district heating system reliability. The problem resides in narrow range of individual model component operating temperatures. For example, the temperature difference of the coolant reaches $90{ }^{\circ} \mathrm{C}$ during simulation. At temperatures of approximately $0{ }^{\circ} \mathrm{C}$, the decrease of modeling accuracy is inevitable. This problem is solved by optimization of thermal component models.

The aim of the present work is to investigate functioning of the building thermal model for further optimization of computing resources and for enhance the functionality and model accuracy.

\footnotetext{
* Corresponding author: tpu_chm@tpu.ru
} 


\section{Research object}

The object of research is a three-floored administration building (total area of $9870 \mathrm{~m}^{2}$ and volume of $35.926 \mathrm{~m}^{3}$ ) which is located in West Siberia (Tomsk city). Heat supply of the building is provided by the central heating unit at the temperature chart $95 / 70{ }^{\circ} \mathrm{C}$. The individual heating unit has been designed under the "independent scheme" [9]. Water is used as a coolant in the heating system internal circuit [10].

The thermal model of the building has been developed the actual operation of the building. The application Simulink of the mathematical package Matlab [11] has been selected as a platform for a model. This choice is motivated by the presence of software wide capabilities: tools for analyzing systems dynamics over time, connection with Workspace and other Matlab applications (for example, Control System Toolbox), simulation of various disturbances (determined or random with different distribution laws) and situations (regular or non-regular, including emergency) which occur at the technical system operation. Block-oriented approach has been applied to simulation and "visual" programming of building heating system in combination with a wide range of Matlab mathematical tools. An extension package Simscape, which implements a "physical" simulation concept [12], has also been applied to develop the model.

\section{Investigation of the building thermal model}

The thermal model structure of the building district heating system is shown in Fig. 1.

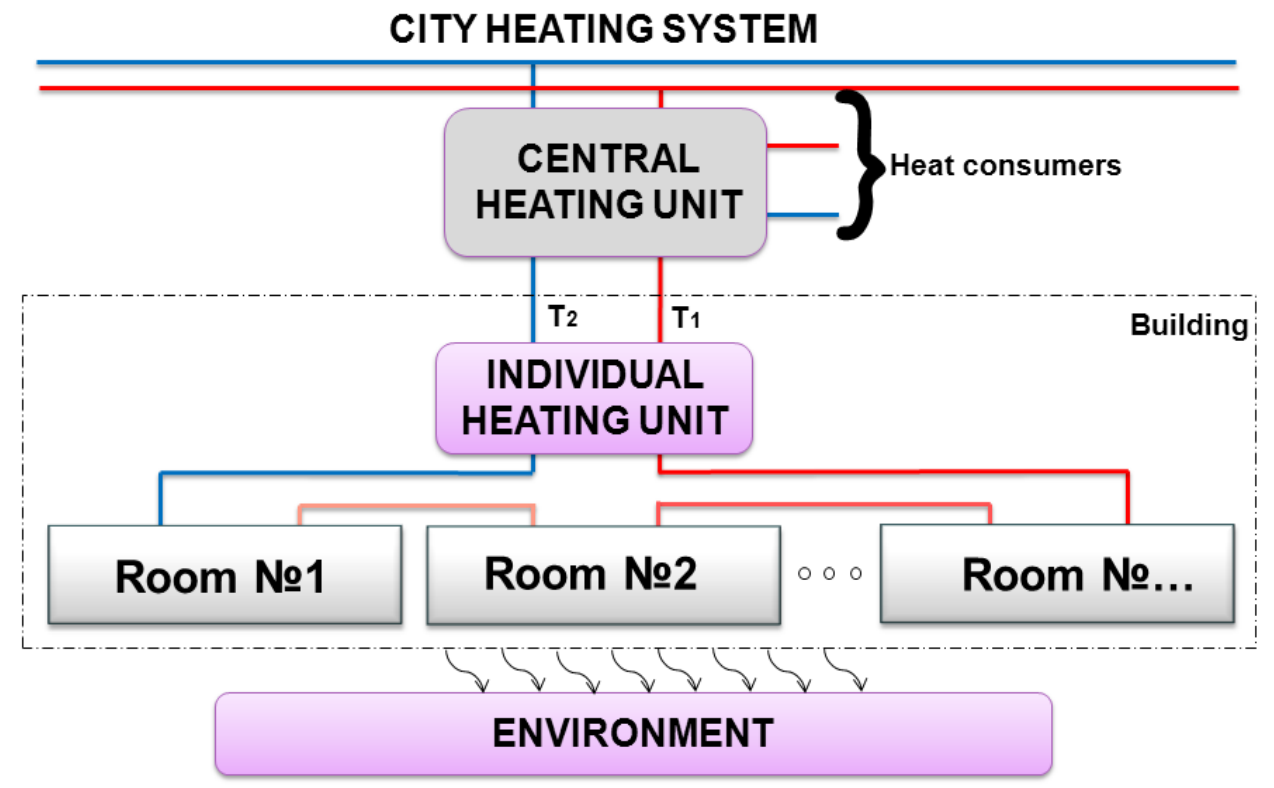

Fig. 1. Structure of the district heating system model: $T_{1}-$ direct coolant temperature, $T_{2}-$ return coolant temperature.

The source of heat supply is a centralized urban heating network. After passing the individual heating unit, a coolant is directed to the building heating system. Generally, the model of an auditorium is characterized by the presence of heat sources and consumers. Thermal energy delivery into the premise derives from heating appliances of the heating system, and its decline - by means of heat transfer processes through exterior envelopments 
to the environment. This approach allows scaling the typical premise model to form the total thermal mode in the building.

Fig. 2 shows an operation algorithm flowchart of the developed thermal model. A model calculation process is made in several stages. At the initial stage, model initialization takes place: connecting the library blocks, defining the signals dimensions, data types, block parameters estimation, as well as optimization of functional elements execution order and the random-access storage allocation to perform the calculation.

Further, initial data loading into the Workspace and Simulink application takes place, after that simulation cycle implementation begins. Each cycle begins with a data import and calculation of simulation time steps values. The fulfillment of uninterrupted heat supply conditions is verified, as well as of heating system operating mode.

After that, model current parameters (temperature, heat flow) are calculated, and a central regulator, relating to the individual heating unit, is activated. Actual heating system heat flow, directed to heat consumers (premise), is calculated. Inside of each premise a local control loop is functioning, headed by room controller, which is responsible for maintenance of the individual thermal mode.

At the stage of heat loss calculation, the thermal processes library Simscape is connected (sequentially, it is implemented the local calculators initialization, calculation of heat consumption and climate parameters of each premise). Further, the output heat flow parameters calculation takes place.

It is important to note that specific functional blocks are calculated in the order, defined in the initialization stage, at each step of simulation. Upon that, there are involved functions, computing the block state variables, state variables derivatives and outputs during the current cycle.

As stop conditions at cyclic simulation there were taken: the finish of preset simulation time, the emergence of "algebraic loops" and other errors during the simulation process, as well as computer available memory shortage.

Automatic processing of obtained results is performed after completing the iterative simulation process. A data export in various formats allows applying various exterior information processing tools.

As a rule, thermal processes in buildings are described by mathematical equations, reflecting the heat transfer stationary mode. Upon that, heat flows are constant and don't depend on time, and thermal processes parameters (for example, coefficients of external and internal envelopments heat transfer, heat irradiation from heating appliance, etc.) are chosen from the reference literature.

In practice a stationary mode is observed only for a very limited time, due to constantly changing external disturbing factors. It is important to note, that the developed model considers dynamics of the real object functioning mode, as well as thermal processes nonlinearity and non-stationarity. 


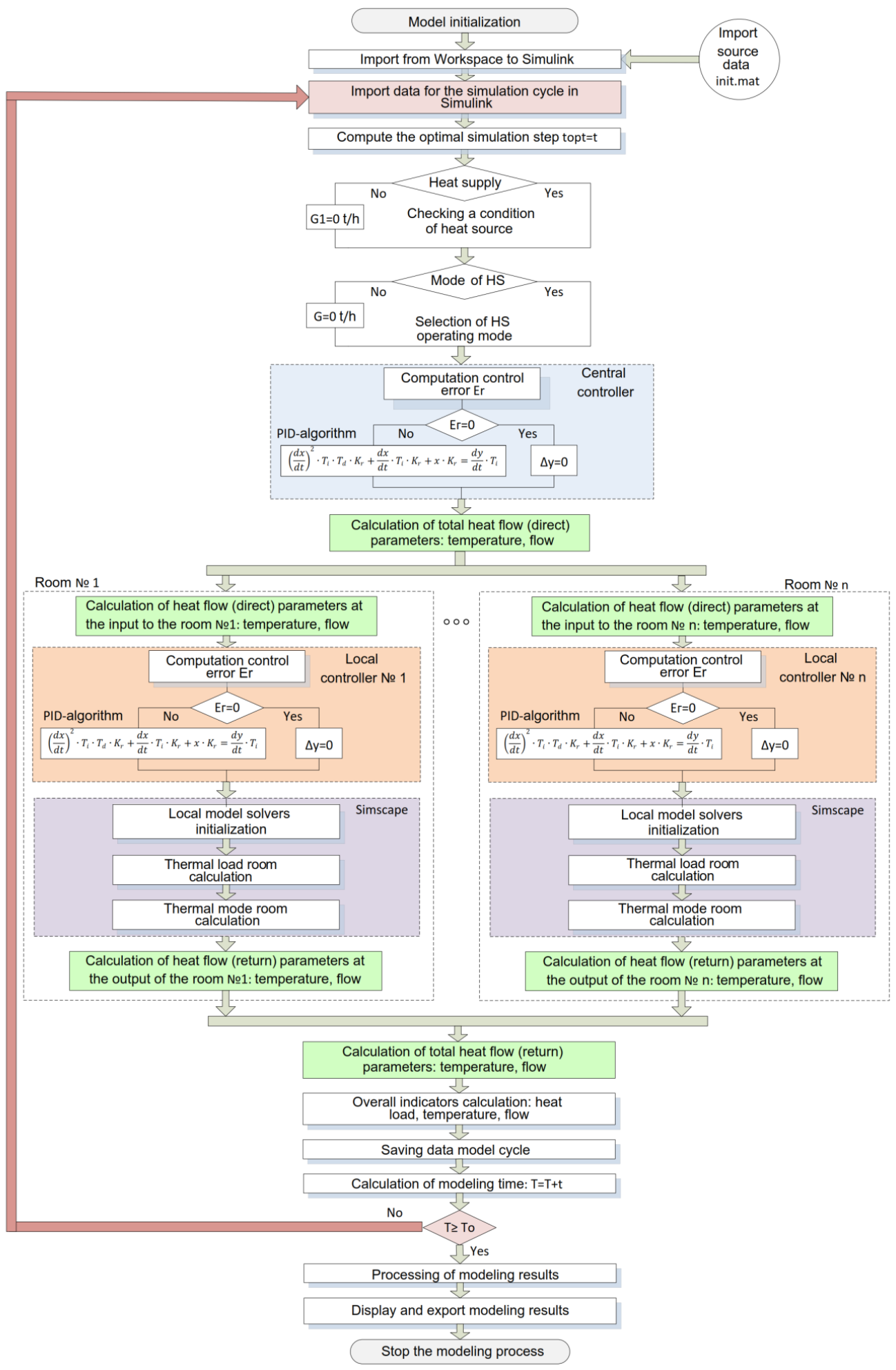

Fig. 2. An operation algorithm flowchart of the thermal model. 


\section{Investigation of building cooling dynamic}

Carried out investigations of building cooling dynamics is the best proof of model performance. Two groups of premise have been selected for prognostic investigation - from the corner and central parts of the building. The following numeration has been admitted:

1) premise no. 1-3 are "corner" on the 1-3th floors respectively;

2) no. 4-6 are "central" premises on the 1-3th floors respectively.

Heating appliances within each group are connected in series (vertical single-tube configuration with overhead coolant distribution). Premises are characterized by the area of $52 \mathrm{~m}^{2}$ and identical layout. "Corner" premises have one additional window. Simulation of heating system emergency operation is at heat supply restriction from the central heating unit. As an example, the results of this simulation of the heating system operating mode at heat supply restriction at 18 o'clock are given below.

Fig. 3 shows the cooling dynamics of the heating system coolant at $T_{\text {ext }}=-40{ }^{\circ} \mathrm{C}$ in case of its continuous circulation. In this case, the minimum water cooling to "threshold" temperature time was recorded for the "corner" premise on the first floor and it was $46 \mathrm{~h} 45$ min. The maximum cooling time of $56 \mathrm{~h} 13 \mathrm{~min}$ is observed near the "central" premise on the first floor. At the absence of coolant circulation the time of its cooling to the critical temperature is comparable to the time of air temperature reduction.

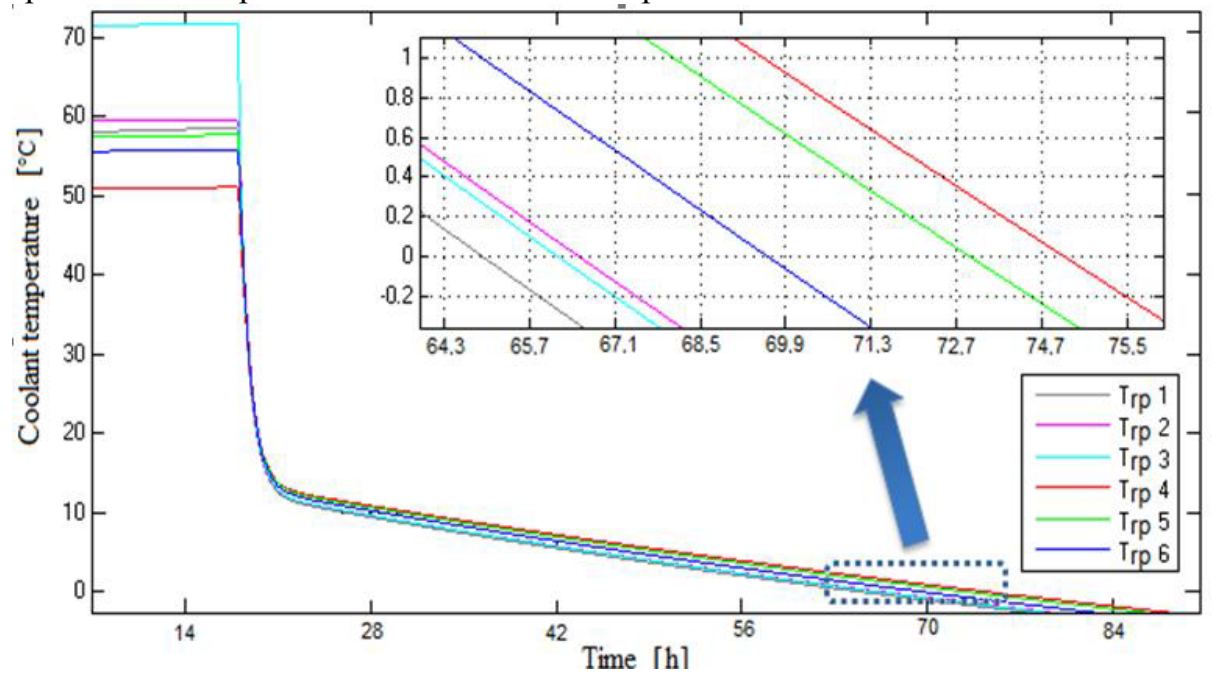

Fig. 3. Cooling dynamics of the heating system coolant at $T_{\text {ext }}=-40{ }^{\circ} \mathrm{C}$ in case of its constant circulation: $T_{\mathrm{rp}}-$ heating system coolant temperature of the $i$-th premise, where $i=1,2, \ldots 6$.

\section{Summary}

A model of the district heating system of the building, which allows investigating the stability of typical buildings and constructions thermal mode (to analyze cooling processes of the heating system coolant, air temperature reduction in premises of various configurations, as well as exterior envelopments) during heat supply failure, has been developed. It is also possible to use the model for energy efficiency investigation of different buildings.

Obtained simulation results (a model, dependences, conclusions and ratios) can be used for preventive measures formulation to optimize the basic operations and procedures, aimed at restoring the thermal modes of buildings and constructions in case of heat supply failure. 
The reported study is supported by the Russian Foundation for Basic Research RFBR (contract 16-38-00628).

\section{References}

1. M. Wallace, R. McBride, S. Aumi, P. Mhaskar, J. House, T. Salsbury, Chem. Eng. Sci. 69, 45 (2012)

2. S. Privara, Z. Vana, E. Zacekova, Energ. Buildings 55, 341 (2012)

3. M.A. Mishin, Polzunovskii vestnik 1, 146 (2010)

4. V.V. Burstev, A.S. Basi, N.M. Baitinger, Polzunovskii vestnik 1, 147 (2004)

5. A.V. Pugovkin, S.V. Kuprekov, D.V. Abushkin, I.A. Zarechnaya, N.I. Muslimova, Lectures of TUSUR University: Control, computing equipment 22, 293 (2010)

6. M. Maasoumy, M. Razmara, M. Shahbakhti, A.S. Vincentelli, Energ. Buildings 77, 377 (2014)

7. P. Lauenburg, J. Wollerstrand, Proceedings of the 11th International Building Performance Simulation Association Conference, 150 (Glasgow, Scotland, 2009)

8. T. Persson, Proceedings of the 45th International Conference of Scandinavian Simulation Society, 199 (Copenhagen, Denmark, 2004)

9. M. Zago, A. Casalegno, R. Marchesi, F. Rinaldi, Energies 4, 2115 (2011)

10. O. Ibrahim, F. Fardoun, R. Younes, H. Louahlia-Gualous, Build. Environ. 72, 259 (2014)

11. M. Kiyan, E. Bingöl, M. Melikoglu, A. Albostan, Energy Convers. Manage. 72, 147 (2013) 